\title{
Secondary Reaction Zone Formations in Pt-Aluminised fourth generation Ni-base single crystal superalloys
}

\author{
A. S. Suzuki ${ }^{*}$, a, C. M. F. Rae ${ }^{1, b}$, R. A. Hobbs ${ }^{2, \mathrm{c}}$ and H. Murakami ${ }^{3, \mathrm{~d}}$ \\ 1) Rolls-Royce UTP/University of Cambridge, Dept. of Mat. Sci. and Met., Pembroke Street, \\ Cambridge, CB2 3QZ, UK \\ 2) Rolls-Royce plc, PO Box 31, Derby DE24 8BJ, UK \\ 3) Surface Kinetics Group, High Temperature Materials Unit, National Institute for Materials \\ Science,1-2-1 Sengen, Tsukuba Science City, Ibaraki, 305-0047, Japan \\ * Current Affiliation: Department of Materials, Loughborough University, UK \\ a: A.Suzuki-Shin@lboro.ac.uk, b: cr18@cam.ac.uk,c: Robbie.Hobbs@rolls-royce.com, d: \\ MURAKAMI.Hideyuki@nims.go.jp
}

Keywords: SRZ, PtAl, Ni-base superalloy, TCP

\begin{abstract}
Fourth generation superalloys are characterised by the addition of Ru which contributes to improved creep resistance whilst improving the microstructural stability. However, Ru additions have a negative effect on coated Ni-base superalloys, promoting Secondary Reaction Zone (SRZ) formation. Formation of a layer of SRZ beneath an aluminised or Pt-aluminised coating has the potential to reduce the effective cross section of a blade by in excess of $100 \mu \mathrm{m}$ or $10 \%$ of the wall thickness. In this paper the effects of alloy composition on the formation of the SRZ in PtAluminised fourth generation alloys were investigated systematically. A series of experimental fourth generation alloys was used having two distinct compositions of $\mathrm{Co}, \mathrm{Mo}, \mathrm{W}$ and $\mathrm{Ru}$ and conforming to a four factorial 'Design of Experiments' model. These alloys showed significant and consistent changes in the SRZ depending on alloy composition. These were in distinct contrast to the effects of these elements on stability in the bulk. Mo was demonstrated to be by far the most effective element suppressing SRZ formation, followed by Co. In contrast, both W and Ru enhance SRZ formation.
\end{abstract}

\section{Introduction}

The latest fourth generation Ni-base superalloys, contain between 2 and 5\% Ruthenium (Ru), which improves the mechanical properties in part by suppressing the formation of deleterious intermetallic Topologically Close Packed (TCP) phases [1,2]. This comes at the cost of the degradation of the oxidation resistance and coatings, such as Platinum Aluminide coatings (PtAl) and MCrAlY, are necessary to protect the turbine blades during service, details of these coatings are given elsewhere [3-5].

The formation of the secondary reaction zone (SRZ) [6-8] is a major problem associated with coated Ni-base superalloys leading to the loss of the coating, and degradation of the properties of coated Ni-base superalloys, and is potentially life-limiting to turbine blades. The SRZ is an intermediate layer formed between an aluminised or Pt-Aluminised coating and the substrate by a discontinuous precipitation reaction similar to recrystallisation. It transforms the metastable aluminium-enriched substrate microstructure into an equilibrium mix of (C), ( $)$ and TCPs. The TCPs coarsen and align perpendicular to the growth direction facilitated by the rapid diffusion path of the high angle boundary. Therefore, the SRZ is associated with poor mechanical properties and provides boundaries allowing a high diffusivity path into the substrate facilitating oxidation and spallation.

Traditionally alloys have been developed principally for mechanical performance and any deficit in environmental performance has been remedied by the application of a coating. However the realisation that the longevity and properties of coated Ni-base superalloys are significantly correlated with alloy composition has placed optimisation of the coating performance as a critical part of alloy development. Understanding how the individual alloy elements affect SRZ morphologies in coated fourth generation Ni-base superalloys contributes to the development of improved Ni-base superalloys. 


\section{Experimental}

The LDSX alloys $[9,10]$ used in this study systematically vary the alloy compositions of Co, Mo, W and $\mathrm{Ru}$ between two fixed values and allow a statistical analysis of the effects of these elements to be made. Table 1 shows the alloy compositions. All alloys were designed to have a density below $9.0 \mathrm{gm} \mathrm{cm}^{-3}$ hence 'Low Density Single crystal'.

The samples used in this paper were prepared from the threaded ends of creep-tested specimens due to the lack of alloy material available. To avoid any interference from the creep tests, specimens were chosen from those test pieces having experienced relatively low temperature test conditions, either $7500^{\circ} \mathrm{C} / 800 \mathrm{MPa}$ or $800^{\circ} \mathrm{C} / 735 \mathrm{MPa}$. Prior to coating the threads were completely removed by grinding. The alloys were grit-blasted and then Pt-coating was applied by electro-plating, followed by annealing at $1100^{\circ} \mathrm{C}$ for $1 \mathrm{~h}$ under vacuum. Pt-Aluminised coatings were applied by a Low Temperature High Activity process at TSTL plc..

Isothermal exposure tests were carried out on the Pt-Aluminised specimens at $1100^{\circ} \mathrm{C}$ for up to 500 hours in air. Microstructures were observed by means of SEM and EBSD. The thickness of the SRZ and the IDZ was measured in each specimen by averaging two representative values from each of eight randomly chosen areas, details of the measurement technique are described in ref. 8 .

Table 1. Nominal Alloy compositions in wt\%.

\begin{tabular}{|l|c|c|c|c|c|c|c|c|c|c|c|}
\hline & $\mathrm{Co}$ & $\mathrm{Cr}$ & $\mathrm{Mo}$ & $\mathrm{W}$ & $\mathrm{Re}$ & $\mathrm{Ru}$ & $\mathrm{Al}$ & $\mathrm{Ti}$ & $\mathrm{Ta}$ & $\mathrm{Hf}$ & $\mathrm{Ni}$ \\
\hline LDSX-1 & 3.0 & 3.0 & 2.5 & 2.9 & 6.2 & 3.5 & 6.0 & 0.3 & 6.5 & 0.1 & $\mathrm{Bal}$. \\
\hline LDSX-2 & 8.0 & 3.0 & 5.0 & 2.9 & 6.2 & 3.5 & 6.0 & 0.3 & 6.5 & 0.1 & $\mathrm{Bal}$. \\
\hline LDSX-3 & 3.0 & 3.0 & 5.0 & 4.8 & 6.2 & 3.5 & 6.0 & 0.3 & 6.5 & 0.1 & Bal. \\
\hline LDSX-4 & 8.0 & 3.0 & 2.5 & 4.8 & 6.2 & 3.5 & 6.0 & 0.3 & 6.5 & 0.1 & Bal. \\
\hline LDSX-5 & 8.0 & 3.0 & 2.5 & 2.9 & 6.2 & 5.0 & 6.0 & 0.3 & 6.5 & 0.1 & Bal. \\
\hline LDSX-6 & 3.0 & 3.0 & 2.5 & 4.8 & 6.2 & 5.0 & 6.0 & 0.3 & 6.5 & 0.1 & Bal. \\
\hline LDSX-7 & 3.0 & 3.0 & 5.0 & 2.9 & 6.2 & 5.0 & 6.0 & 0.3 & 6.5 & 0.1 & Bal. \\
\hline LDSX-8 & 8.0 & 3.0 & 5.0 & 4.8 & 6.2 & 5.0 & 6.0 & 0.3 & 6.5 & 0.1 & Bal. \\
\hline
\end{tabular}

\section{Results}

Fig. 1 shows cross-sections of two as-aluminised LDSX alloys. All the alloys consist of a coating layer, an Inter Diffusion Zone (IDZ) and even at this very early stage a layer of SRZ. The SRZ morphology varied with the alloy: LDSX-1, 4, 5 and 6 showed a continuous SRZ, whilst LDSX-2, 7 and 8 showed sporadic areas of SRZ and LDSX-3 showed no SRZ but did show TCP phases in the substrate.

Samples were examined after annealing at $1100^{\circ} \mathrm{C}$ for 20,50100 and $500 \mathrm{~h}$. Fig. 2 shows LDSX-7 and LDSX-6 after 100h and Fig. 3 shows cross-sections of all alloys after 500h exposure. All specimens showed degradation of coating layer, exemplified by the broken surface and void formation. The SRZ morphologies retained the same trends observed in the initial samples. With the high Mo alloys LDSX-1, 4, 5 and 6 showing thick continuous SRZ and the others (low Mo) sporadic or no SRZ (LDSX-3).

The SRZ growth rate was plotted in Fig. 4. The alloys again fall into two distinct categories: the sporadic SRZ forming alloys (high Mo) showed almost half of SRZ penetration depth compared to the continuous SRZ forming alloys. Growth rates in first 50h for the low Mo alloys are compatible with those for the high Mo alloys, with the exception of LDSX-3, as seen in Fig. 3. However, after $100 \mathrm{~h}$, the growth rates of the sporadic and continuous SRZ formers diverge with the penetration depth almost double in the continuous SRZ alloys (low Mo) after $500 \mathrm{~h}$. 


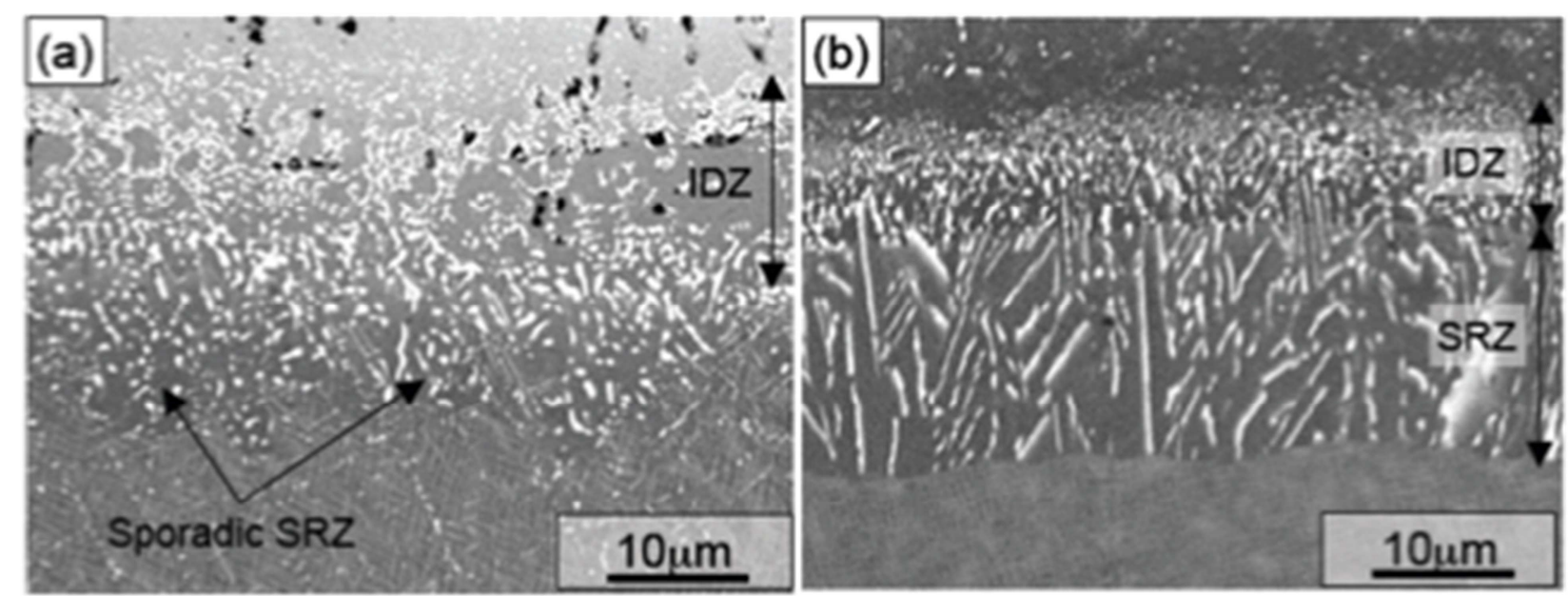

Figure 1. Cross sections of (a) LDSX 2 and (b) LDSX-6 As aluminised showing sporadic and continuous nucleation.

Up to $100 \mathrm{~h}$ exposure, all the low Mo alloys showed a similar SRZ growth rate, however, after this, LDSX-1 and 5 stopped growing, whereas LDSX-4 and 6 continued to grow. These alloys have low and high $\mathrm{W}$ respectively with high $\mathrm{W}$ encouraging further SRZ formation. This behaviour is confirmed after a total $2000 \mathrm{~h}$ exposure of the alloys LDSX-1 and 6 which differ in their $\mathrm{W}$ and $\mathrm{Ru}$ content, the SRZ in LDSX1 (low W, Ru) remaining static and the SRZ in LDSX-6 almost doubling in thickness to over $250 \mu \mathrm{m}$. The alloy LDSX-5 showed unique behaviour: the SRZ continuing to grow without the precipitation of TCPs, i.e. the substrate alloy is stable with respect to TCP precipitation, Fig. 3.
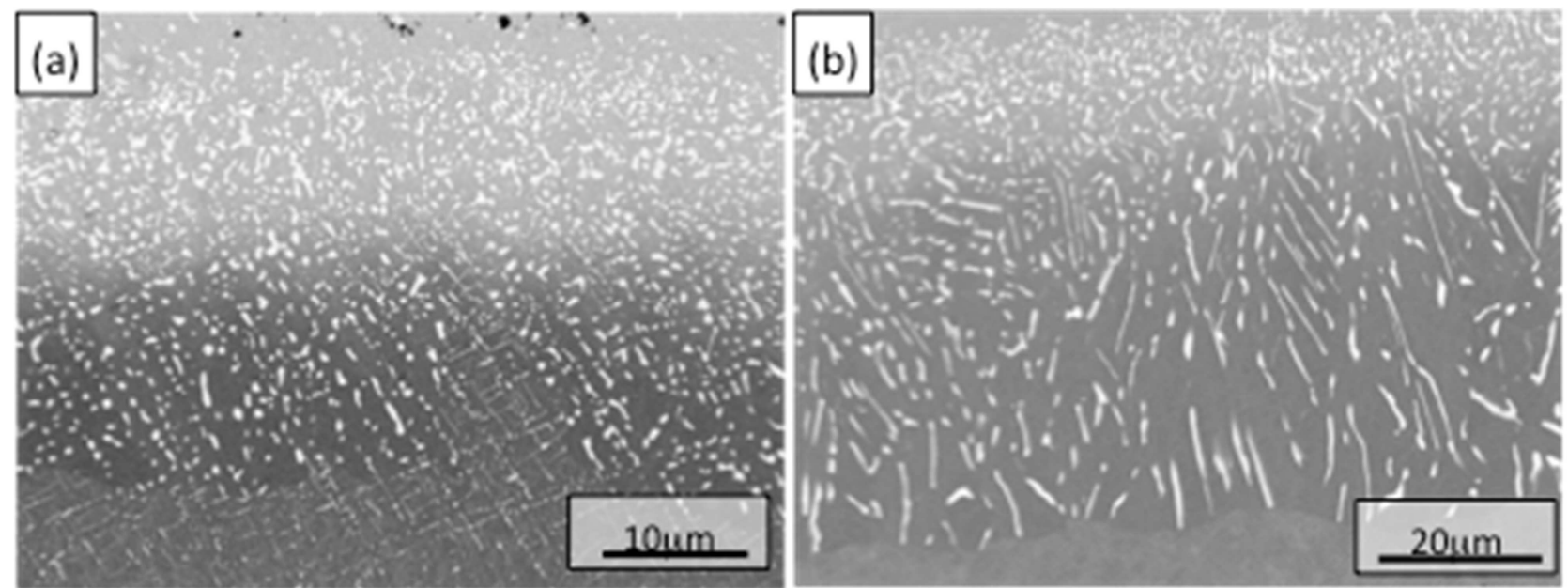

Figure 2. (a) LDSX-7 and (b) LDSX-6 after $100 \mathrm{~h}$ exposure at $1100^{\circ} \mathrm{C}$

These 8 alloys were devised as a two level four factorial design of experiments series and the penetration depth at each of the exposure times were analysed using MiniTab 15 [11]. The probability of statistical significance was set at $90 \%(\langle=0.1)$ and nominal compositions were used for this analysis. Of the elements only Mo showed a strong effect suppressing the SRZ which strengthened as the annealing time increased. Co showed a small negative correlation with the thickness of the SRZ but below the level of statistical significance. The other elements $\mathrm{W}$ and $\mathrm{Ru}$ showed weak and inconsistent effects over the full series. 


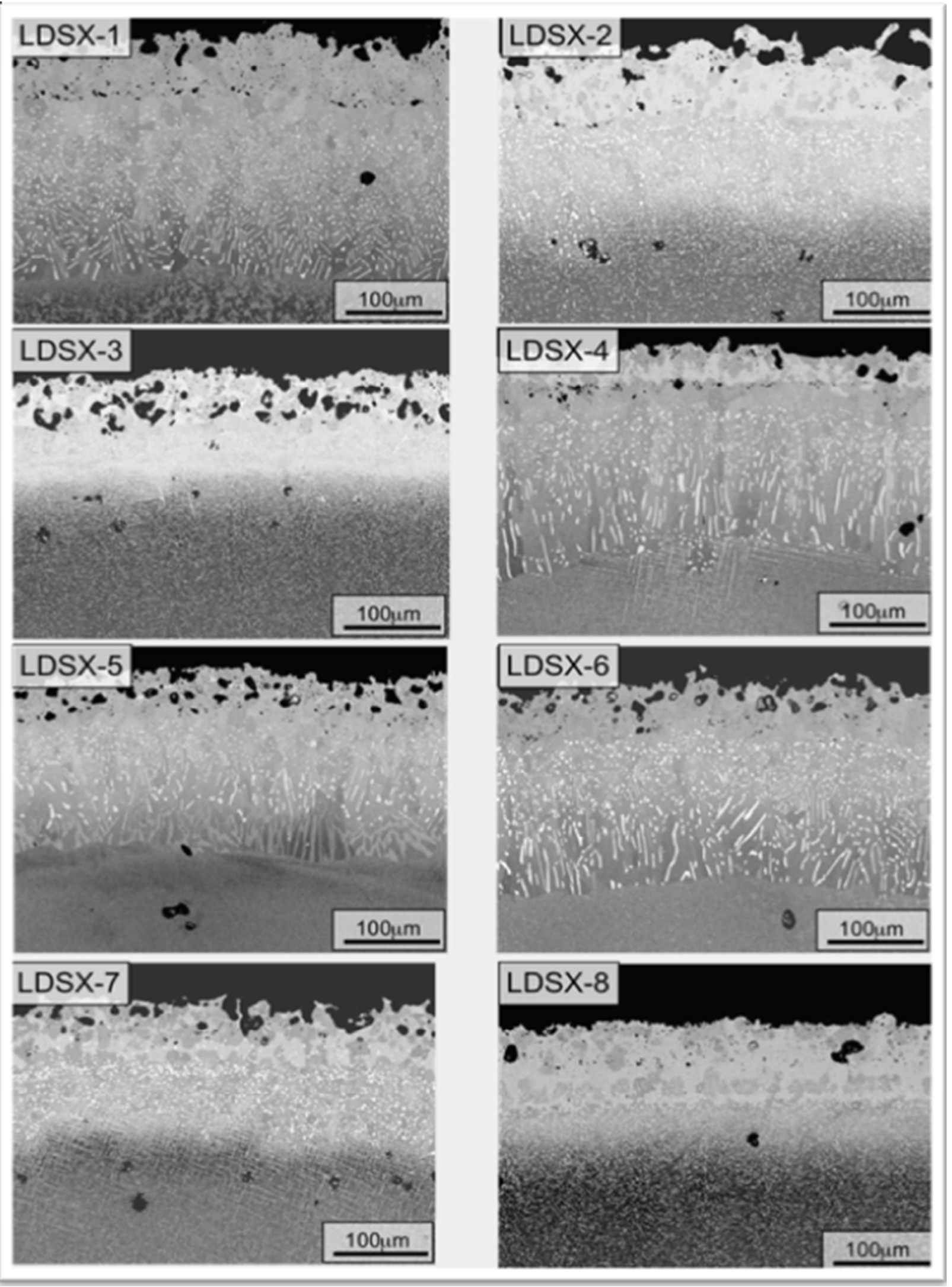

Figure 3. Microstructure of all the alloys after $500 \mathrm{~h}$ exposure at $1100^{\circ} \mathrm{C}$. 

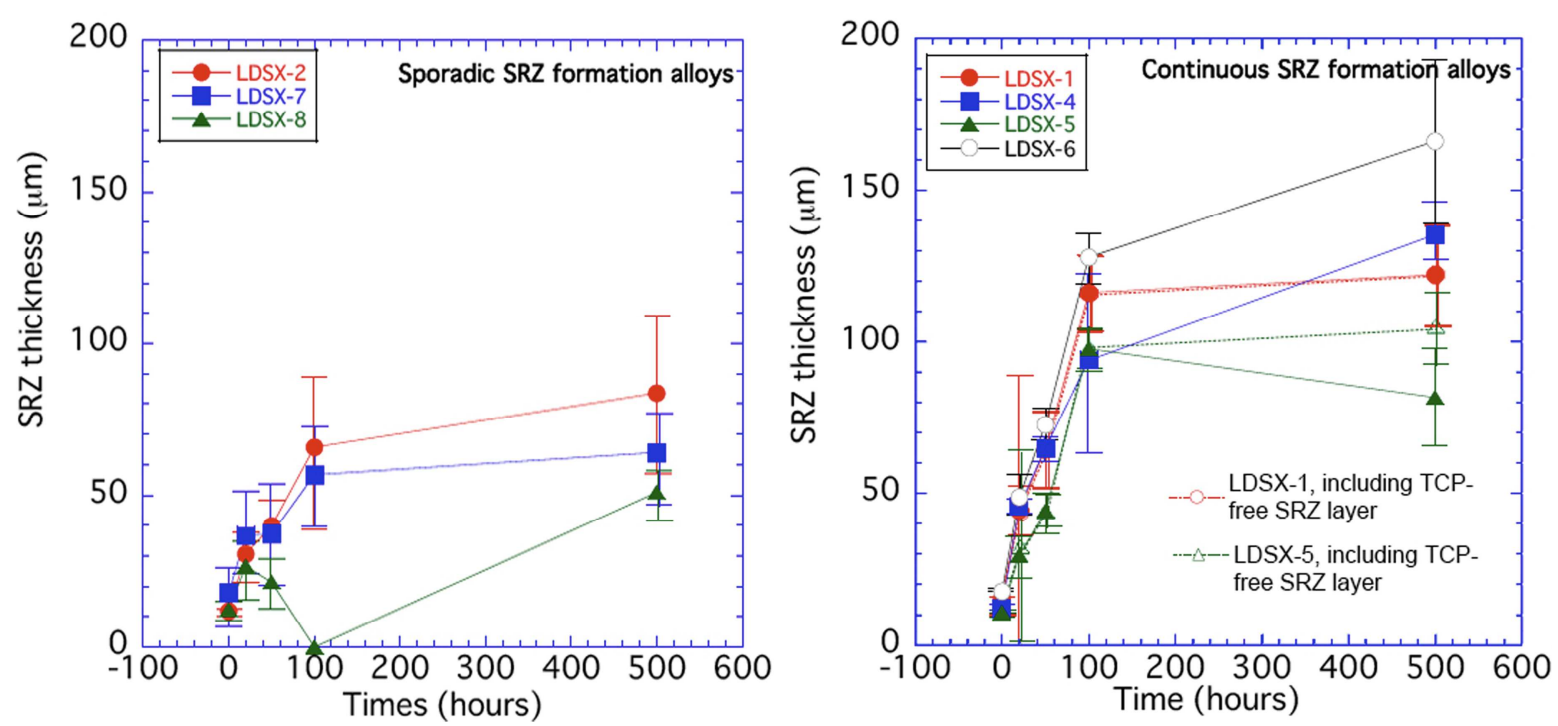

Figure 4. Graphs of SRZ depth as a function of exposure time at $1100^{\circ} \mathrm{C}$; Sporadic and continuous SRZ plotted separately.
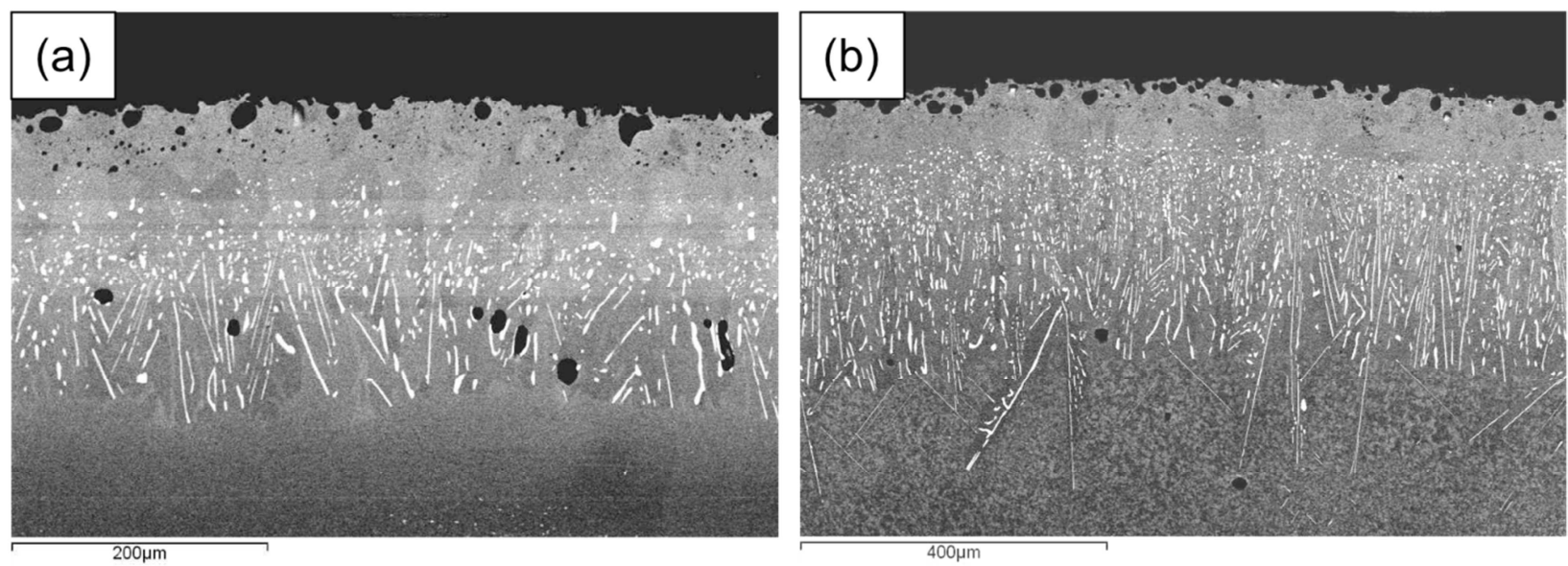

Figure 5. Microstructures of the alloys (a) LDSX-1 and (b) LDSX-6 after 2000h exposure showing the effect of $\mathrm{W}$ on further SRZ growth.

\section{Discussion}

The alloys in this series provide an excellent opportunity to isolate the effects of the four alloying elements $\mathrm{Mo}, \mathrm{Co}, \mathrm{W}$ and $\mathrm{Ru}$ on the formation and growth of the secondary reaction zone. Previous investigations have highlighted the effects of Re [6] as the SRZ was virtually unknown in first generation and rare in second generation single crystal alloys. A previous study by the present authors focussed on the effects of $\mathrm{Ru}$ interacting with the effect of the preparation of the surface prior to coating. This study [8] of alloys containing $1 \%$ Mo shows that $\mathrm{Ru}$ appears to promote the formation of the SRZ by increasing the amount of nucleation and encouraging growth. In part the increased growth rate is a result of the increased stability of the substrate and the absence of TCP phases in the substrate to interrupt growth.

The present study shows a strong effect of Mo inhibiting the formation and growth of the SRZ with one of the high Mo alloys showing no SRZ whatsoever and the other three, sporadic nucleation and diminished growth. Amongst the group of low Mo alloys showing continuous SRZ, (LDSX-1, $4,5,6)$ high $\mathrm{W}$ promotes SRZ growth particularly at long annealing times. The effect of W in the other group of alloys with no or sporadic growth of SRZ is the opposite with the two high Mo, high $\mathrm{W}$ alloys, LDSX-3 and 8, showing the least SRZ growth of all. The overall effect of $\mathrm{W}$ is hence neutral in the statistical analysis. 
In comparison to $\mathrm{W}$ and $\mathrm{Mo}$ the effects of $\mathrm{Ru}$ and $\mathrm{Co}$ are greatly reduced. Previous work on alloys with Mo levels below 3\% has shown that Ru increases the nucleation rate and the growth rate of the SRZ [8]. Co has the opposite effect reducing SRZ formation when varied between 2 and $12 \mathrm{wt} \%$ in an alloy containing 2.2\% Mo, however the change in Co from 3 to $8 \mathrm{wt} \%$ in the LDSX alloys is rather small in comparison. Hence the effects of increased $\mathrm{Ru}$ and Co on the SRZ are expected to be opposite. In the present work and focussing on the low Mo alloys, any increase in nucleation rate caused by $\mathrm{Ru}$ is ineffective in changing the thickness of the SRZ as it already forms extremely easily, and as these alloys are also reasonably stable, there is little effect of the TCPs in the substrate inhibiting growth. At the higher levels of Mo in LDSX-2, 3, 7 and 8, a comparison of LDSX-3 with 8 and of LDSX-2 with 7, shows that these are very similar and dominated by the Mo and $\mathrm{W}$ composition levels.

It is striking that the effect of Mo on the formation of the TCPs in the SRZ is the opposite of that in the substrate [12], This is evident from the earliest observations immediately following the initial $1 \mathrm{~h}$ anneal after aluminisation. At this point the TCP precipitation in the substrate is limited with LDSX-3 showing some occasional large planar $\int$ TCPs. Hence it is not the physical presence of the TCPs in the substrate causing the reduction in SRZ formation, although there may be some later effects on growth in the more unstable alloys. Thus the two most effective strategies for increasing the stability of the alloy, i.e. increasing $\mathrm{Ru}$ and reducing Mo both lead to very rapidly forming, continuous layers of SRZ form the earliest point of entry into service. It is essential to consider this in the design of new alloys where coatability is essential to alloy viability.

\section{Conclusions}

A systematic 'Design of Experiments' series of alloys was Pt-Aluminised and investigated in terms of the SRZ morphology, microstructural evolution and nucleation mechanism. Examination of the resulting microstructures leads to the following conclusions.

- The alloys divide clearly into two categories, those with Mo at $2.5 \mathrm{wt} \%$ showing early and continuous SRZ formation and those with $5 \mathrm{wt} \%$ showing little or sporadic SRZ.

- For the low Mo alloys, high W promotes continued and deep penetration into the substrate.

- The effects of Co and Ru are opposite but are small in comparison at the levels added in these alloys.

\section{Acknowledgements}

The authors would like to acknowledge the EPSRC in funding this work under the DARP project GR/S26156/01 and Roll-Royce plc for their vital support both in terms of materials and expertise. We would also like to acknowledge the role of Dr. Sammy Tin in the design of the LDSX alloy series.

\section{Reference}

[1] R. A. Hobbs, L. Zhang, et al. : Met. and Mat. Trans. A, vol. 39A(5), p. 1014.

[2] A. C. Yeh, C. M. F. Rae and S. Tin: Superalloys 2004, Warrendale, TMS, 2004, p. 677.

[3] G. R. Krishna, D. K. Das, et al. , Mat. Sci. and Eng. A, vol. 251, 1998, p. 40.

[4] J. Angenete and K. Stiller: Mat. Sci. and Eng. A, vol. 316, 2001, p. 182.

[5] M. J. Stiger, N. M. Yanar, et. al.: Z. Metalkd, vol. 12, 1999, p. 1069.

[6] W. S. Walston, J. C. Schaeffer and W. H. Murphy: Superalloys 1996, Warrendale, TMS, 1996, p. 9. [7] J. C. Zhao, J. A. Pfaendtner, et. al. : United States Patent, 6921586, 2005

[8] A. Suzuki, C. M. F. Rae, et. al. : Superalloys 2008, Warrendale, TMS, 2008, p. 777.

[9] K. N. Grubb, C. N. Jones, et. al. : UK Patent GB2427617A, 2006

[10] R. A. Hobbs, G. J. Brewster, et. al. : Superalloys 2008, TMS, Warrendale, 2008, p. 171.

[11] Minitab Inc., Minitab Stat Guide http:/www.minitab.com

[12] H.T. Pang, R.A. Hobbs, H Stone and C.M.F. Rae, 2010, Ibid 